\title{
QT dispersion and acute cerebrovascular accident
}

Sir,

The original contribution of Rahar et al. on the relation between QT dispersion and cerebrovascular events presents substantial perspectives regarding the pathophysiology of cardiac abnormalities in stroke. ${ }^{[1]}$ We would like to state that the study results revealing significantly higher QT dispersion in patients with acute stroke as compared to healthy controls $(P>0.05)$ in survived group due to expired patients $(P<0.05)$ and, moreover, correlation of QT dispersion with neurological status of the patients (National Institute of Health Stroke Score calculated at presentation while Modified Rankin Scale at discharge) were impressive. Although there is increasing evidence supporting the relation of QT dispersion and acute stroke, still there is not a consensus on this subject as well as underlying mechanisms remain to be elucidated. ${ }^{[2]}$ Hence, the report by Rahar et al. constitutes a unique study yielding several statistically significant analyses in aspects of association of QT dispersion in acute stroke and remarkably its utility on the prognosis.

However, we would like to comment the article in some aspects hoping to provide new perspectives to this issue. First, we appreciate their patient involvement criteria such as the exclusion of patients with prior history of cardiovascular disease, patients taking medication to affect QT. This method provides a more rational interpretation of the study results of QT dispersion in association with pure stroke. Based on their results of positive correlation of QT dispersion with stroke, they emphasized some hypotheses such as dysautonomic activity, increased sympathetic activity as the responsible mechanisms of QT dispersion. On the other hand, the reason why mortality of these patients was higher in QT dispersed ones is not discussed. A probable explanation might be that cardiac rhythm abnormalities might have resulted in sudden cardiac death in these patients group. However, patients included in the study have not previous history of cardiovascular disease which decreases this possibility. Furthermore, another explanation may be the effect of some specific effected brain regions in stroke, such as insula and parietal lobe those have been suggested to be associated with adverse cardiac events. ${ }^{[3,4]}$ Remarkably, as the relation between QT dispersion and stroke mortality has been mentioned in only a limited number of reports, ${ }^{[2,5,6]}$ underlying pathogenesis of mortality remains unclear in literature. In a unique report of Huang et al., arrhythmic death was not evident in QT-dispersed patients group ${ }^{[5]}$ which also suggests other underlying processes for the cause of mortality. At this point, a crucial argument may be that if the poor prognosis (and higher mortality) in QT group is associated with a primary cardiac pathology or if the poor prognosis is rather related to its (QT dispersion) reflection value of severity of neurological events. The other aspect, in another substantial report ${ }^{[5]}$ as referred by the authors, QT dispersion was found at first $24 \mathrm{~h}$ of stroke, but this difference had disappeared at $72 \mathrm{~h}$ electrocardiogram. Also, an interesting question may be that how this effect of temporary change (QT dispersion) results in worse prognosis and higher mortality in long period. We think that reporting the data of causes of mortality in the study of Rahar et al. might provide crucial data on these arguments.

Second, another important topic of discussion is the association of lateralization and localization of stroke and cardio-autonomic dysfunction. Some researchers have addressed higher rates of QT dispersion in right hemisphere strokes. ${ }^{[7,8]}$ They associated this with right hemisphere's greater tendency to cause arrhythmia. Furthermore, although some specific brain regions involving insula and parietal lobe have rather been associated with cardiac arrhythmia in stoke, there is not a consensus in this issue. ${ }^{[3,4,9]}$ We wonder if the author may include the data of stroke lateralization which seems to be valuable in these respects.

Finally, we would like to state that considering the above mentioned questions about the association of QT dispersion and stroke prognosis as well as very limited number of studies in this respect, addressing such an algorithm of cutoff values of QT dispersion to predict the mortality may be too ambitious and misleading. However, we agree that the results of this study are extremely valuable and clarification of these results in future larger case studies may add crucial knowledge to the pathogenesis of this association, and as further, these studies may also provide practical approaches in clinical use.

\section{Financial support and sponsorship \\ Nil.}

\section{Conflicts of interest}

There are no conflicts of interest.

Halil Onder, Sahin Hanalioglu ${ }^{1}$

Departments of Neurology and ${ }^{1}$ Neurosurgery, Hacettepe University Medical School, Sıhhıye, Ankara, Turkey

Address for correspondence: Dr. Halil Onder, Department of Neurology, Hacettepe University Hospital, Sıhhıye, Ankara 06010, Turkey. E-mail: halilnder@yahoo.com 


\section{References}

1. Rahar KK, Pahadiva HR, Barupal KG, Mathur CP, Lakhotia M. The QT dispersion and QTc dispersion in patients presenting with acute neurological events and its impact on early prognosis. J Neurosci Rural Pract 2016;7:61-6.

2. Lederman YS, Balucani C, Lazar J, Steinberg L, Gugger J, Levine SR. Relationship between QT interval dispersion in acute stroke and stroke prognosis: A systematic review. J Stroke Cerebrovasc Dis 2014:23:2467-78.

3. Rincon F, Dhamoon M, Moon Y, Paik MC, Boden-Albala B, Homma S, et al. Stroke location and association with fatal cardiac outcomes: Northern Manhattan Study (NOMAS). Stroke 2008;39:2425-31.

4. Colivicchi F, Bassi A, Santini M, Caltagirone C. Cardiac autonomic derangement and arrhythmias in right-sided stroke with insular involvement. Stroke 2004;35:2094-8.

5. Huang $\mathrm{CH}$, Chen WJ, Chang WT, Yip PK, Lee YT. QTc dispersion as a prognostic factor in intracerebral hemorrhage. Am J Emerg Med 2004;22:141-4.

6. Bicakci S, Donmez Y, Ozeren A, Acarturk E. QT dispersion on ECG in acute ischemic stroke and its impact on early prognosis. Neurosciences (Riyadh) 2008;13:366-9.

7. Afsar N, Fak AS, Metzger JT, Van Melle G, Kappenberger L, Bogousslavsky J. Acute stroke increases QT dispersion in patients without known cardiac diseases. Arch Neurol 2003;60:346-50.

8. Chugh SN, Garg A, Yadav A, Yadav S. QT-dispersion in patients with stroke without known cardiac disease. JIACM 2011;12:102-5.

9. Laowattana S, Zeger SL, Lima JA, Goodman SN, Wittstein IS, Oppenheimer SM. Left insular stroke is associated with adverse cardiac outcome. Neurology 2006;66:477-83.

This is an open access article distributed under the terms of the Creative Commons Attribution-NonCommercial-ShareAlike 3.0 License, which allows others to remix, tweak, and build upon the work non-commercially, as long as the author is credited and the new creations are licensed under the identical terms.

\begin{tabular}{|l|l|}
\hline \multicolumn{2}{|c|}{ Access this article online } \\
\hline Quick Response Code: & Website: \\
\hline & www.ruralneuropractice.com \\
\cline { 2 - 3 } & \\
\hline
\end{tabular}

How to cite this article: Onder H, Hanalioglu S. QT dispersion and acute cerebrovascular accident. J Neurosci Rural Pract 2016;7:612-3. 